\title{
Message Design: Color Impact and its Effectiveness on Designing Instructional Infographic
}

\author{
Dalia Alyahya \\ Educational Technology Department, \\ College of Education, \\ King Saud University \\ Reham Nasser \\ King Saud University
}

\begin{abstract}
This study aims to contribute to the development of message design. This designing is aimed to enhance student memory and support their knowledge recall. Therefore, the study assesses the impact of colors (Red-Green- Purple-Cyan) and their effect when used in designing educational infographic message for students with relation to their retrieve functionality. To achieve the goal of the study, the researchers follow the quasi-experiment methodology, using five tools which vary in terms of words, sentences, and images. A total of 87 female students at King Saud University from different fields (Islamic Studies, Quranic Studies, Art Education, Special Needs Education, Psychology and Computer Science). The study found that there is a significant relationship $(0.05 \geq \mathrm{a})$ between the colors usages in designing educational infographic message and level of students' recall for students. It also found the significant level at $(0.05 \geq \alpha)$ impact of colors, particularly for red, on recall's level of the students when used in designing educational infographic message. Also, the researchers recommend studying different colors in divergent fields to present an educational message such as educational media, educational software, educational websites, images, books, social networking etc. which can enhance the learning competence of the students.
\end{abstract}

Keywords: Colors; Instructional Message Design; Instructional Design; Infographic; Recall Level.

\section{Introduction}

Visuals are of prime importance to the human beings given its significance in terms of senses. This sense allows the individual to perceive and view the actual world in its real form. The visual system is referred to as a complex system, 
which collects huge amounts of visuals while simultaneously processing them. It provides channel beams with a high range of human cognitive centres, that possesses a high level of visual treatment, observation, and perception as well as the relatedness which prevails among them (Simon, 2014). It has been mentioned in an infographic power book that $50 \%$ of the human brain is specialized for visual functions, indicating that the sight nerve cells encompass a huge part from the human body. The nerve cells, which are specialized for visual activity, consisting of 150 million cells; whereas touching and hearing nerve cells represent a percentage of $8 \%$ and 3\%, respectively. Human being utilizes various oral /non-oral symbols for communicating with each other (Nasir, 2009). Recently, their indulgence in non-oral symbols (i.e. visuals) in the educational process has amplified. These visual components in the education sector are represented in the form of Instructional Design, which is defined as a component of modern science, which initially appeared in the late twentieth century. The design mainly focuses on the contents of educational situations, such as its material, machine, strategies and instructional messages (Pettersson, 2013).

In the educational setting, the instructional message design is considered an important component in the communication process between the teacher and the learner. In other words, it is defined as a signal unit inclusive of all forms like pictures, words, or signs that are used to improve someone's behaviour. (AL Juhani, 2015). The significance of infographic messages designing and its utilization as an educational tool emerges from its method which improves learner's performance. This project the significance of the instructional designers 'concerns pertaining to designs which are centred on deliverance of adequate knowledge to learners. Designing instructional infographic is based on many scientific fields; such as educational, psychology, original functions, communication, and art theories. (Al Juhani, 2015).

The infographic is considered as a type of modern instructional delivery means, where colors are considered as its key elements which must be centralized around the recipient (Shaltout, 2016). Color helps in differentiating the world around us where people acquire the largest amount of surrounding information through these visuals. Many studies have proven that there is a relationship between colors and the process of recalling (Kang, 2016; Shaltout, 2016). This indicates that colors possess different abilities to capture the recipient's attention, to enhance his memory, and to contribute to clarifying comparisons and to conduct an information analysis. Selecting basic colors such as purple, red, yellow, and Cyan are helpful in attracting human attention. Along with it, color is considered as the most effective visual features which help in encoding memory and in increasing the limit for storing information. Psychologists have found that memory can work better if it analyses color stimulants other than black and white. It is because color effectively captures the human vision, which leads to better communication as well as memorization, an important part of the human mental process.

The process of forgetting and not recalling a certain thing at a particular time is considered as a primary mental human process. Many mental processes rely on 
the brain, such as learning, cognition, problem-solving (Bruner, 2017). Without it, the received knowledge is perceived as the information which he/she has received for the first time; as a result, learning does not proceed (Resnick, 2017). The process of recalling serves as an interesting area given the fact that learning mainly relies upon it (Rumelhart, 2017). A human 80\% learning takes place through recalling, besides its ability to match information in terms of its structures or frames which enable the brain to recognize it. The instructional designer must be familiar with the effective instructional message design principles that supports learner's recalling process. Additionally, its design focuses on signals and symbols to ensure that they are saved in memory.

An important element of the instructional message design is the colors which are integrated into it based on its impact upon the recipient (Shaltout, 2016). Using colors, a designer is able to attract attention and increase the effectiveness of the text being read. Moreover, it reduces the loud of cognitive process on memory. This point is considered a starting point for the instructional designer in crafting an instructional message, which acts as a stimulus and motivating factor for the learner to achieve the necessary level of understanding (Moneah, 2010). These factors must have the ability to motivate attention through senses such as color. Studies have revealed that colors affect the level of attention while also increasing the excitement level dramatically (Khamees, 2013). In addition, it leads to emotional change that enhances controlling processes and improves memory to save information inside memory in a simple pattern for a short time. Designing an educational infographic message must include several things such as choosing attractive and suitable colors for content (Shaltout, 2016).

By reviewing previous studies and related educational research, it was found that there exists paucity of information related to instructional message designing particularly in the context of recalling process using colors. Given this, the present study has emerged with the aim to identify the impact of colors in designing the educational infographic message for improving the recalling process among female students. This study aims to contribute to developing instructional message design to remember and support information recalling for the learner. This happens by examining the impact of using (red - violet - green Cyan) colors in designing educational infographic message upon recalling the process for students. The importance of this study is based on specifying infographic design for an instructional message that supports the recalling process. One of its main teaching objectives is to enhance the learner's ability to remember and recall what he/she has previously learned, a basic level for Bloom's Taxonomy.

Although the recalling level is the lowest levels in mental Bloom's Taxonomy, it is still an important and essential knowledge level. It includes understanding, applying, analysing, creating, and all relevant processes (Al-Khalifa, 1435). Human brain receives a lot of information through different sense at the same moment (Krum, 2013). Therefore, it is important that instructional designer in designing instructional messages to recognize a human behaviour towards receiving information, as well as, knowing how the human mind recall and treat information (Zghoul, 2015). There is a need to find certain methodologies that 
help to ease information's transmission from working and short-term memory to the long term-memory in order to be retrieved easily (Zghoul, 2015). One of these methodologies is using specific colors during designing instructional message, to help the learner notices the change in text color. The study intends to provide an answer to two questions, they are:

1. Does a significant relationship exist between the used (red - green purple - Cyan) colors in designing educational infographic message and level of recall for King Saud University students?

2. Are there significant differences in recalling level for King Saud University's students, due to using (red - green - purple - Cyan) colors in designing educational infographic message?

In addition to this, the study is limited to the framework which solely focuses on the effect of red, violet, Cyan and green color for designing educational infographic message for recalling the learned content. Further, the study is also limited in terms of population as its only recruited students from a single university such as Faculty of Education, King Saud University. Moreover, the outcome achieved is further limited to the region of Riyadh, Saudi Arabia. It also follows a time limit such as it included students who were enrolled in the second semester of the 2018 academic year.

\section{Theoretical Framework}

An instructional unit is the design process artifact that represents an interaction between the learner and the instructional materials (Morrison, Ross, Kalman, and Kemp, 2011) Infographics, in the form of instructional materials, can serve as the interface between the learner and instructional unit. Thus, multiple research in the instructional design and technology has furnished the theoretical basis for designing and creating effective instructional interface.

\subsection{Instructional message and infographic}

Instructional message is a communication channel between teacher and learner. It is referred to as the art of designing communication science to achieve educational goals. It means that all the different styles that are used to contact the sender with the receiver. Moreover, it is defined as all different types of signs and symbols that describe certain behavior in one of the following educational fields: Cognitive field, emotional field, and physical-psycho field to achieve learning process (Al Seif, 2012). Designing of instructional message process is defined as a special planning process in forming the physical version. It includes applying message, principles of attention, perception, and recalling by leading special material for a message to achieve communication between sender and receiver (Al Seif, 2012). He also indicated that design and the outer shape of the instructional message are important than its content. When an instructional message has an appealing design, it affects positively on understanding, recalling and retrieval operations. It is because short-term memory is directly 
affected by colors which are then stored in long-term memory of the individual. Concerning this, it should be assessed in light of the latest methods that improve the human mind capabilities for gaining maximum benefits through understanding.

Designing of the instructional message must hold three basic operations effectively: Attention, perception, and recall which are required to achieve effective communication between teacher and learner (Schunk, 2012). As a part of the effective design for the instructional message, suitable designs must be chosen which trigger the nerve system in our body. Instructional designer handles designing instructional message with signs and symbols to ensure it stored in memory with varied forms of instructional messages, such as audio, text, image, video, symbols, signals and others (Flagg, 2013). Shaltout (2016) has defined infographic as visual embodiment of information or ideas that are delivering complex information to the public, in a way that enables them to be understood and absorbed quickly. It highlights the following steps while designing infographic is mandatory:

1- Studying and analyzing stage is achieved by describing the current situation and expected situation. Difference between both is called the need.

2- Educational content analysis; Content is analyzed into small parts then minimize infographic is conscripted, which is designed for all parts or collected in the enlarged infographic.

3- Identify educational goals; they are formulated in a behavioral manner by specifying the desired type of behavior and determine the acceptable level of performance, as well as, determining the learning circumstances.

4- Analyze learners' characteristics to know the prior knowledge, then based on that learning, the starting point is determined.

5- Design phase includes; writing educational goals, writing scientific content, specifying font's colors, shapes, and designing interactive elements of content.

6- Production stage begins by collecting visual elements from icons, shapes, and lines. It happens by determining the program that is used in building an infographic, by considering the sequence and correctness of information, and by using correct language.

7- Assessment Stage in which infographic is judged by experts to ensure scientific content is represented and achieved perfectly learning goals to ensure the infographic validity for presenting to the learners (Shaltout, 2016). 


\subsection{How does the human mind see the information?}

A human is an optical creature that can see and live in a visual world. Its $70 \%$ of the external influences are received by eyesight, and $50 \%$ of mind device is dedicated for treating objects (Evans, 2016) such as vision, colors, shapes, motion, and spatial awareness (Krum, 2013). Mind treats intricately texts. Each letter in a text is a symbol, and mind needs to decrypt these symbols by matching text with symbols inside memory to transform words into sentences, then to paragraphs. Despite the complexity of these processes, this process occurs in one second. This is called the theory of information processing, which focuses on mental processes that are performed by the person to treat information that he/she receives from outside. This theory is based on chunks concept and short-term memory capacity. It is a division of information into meaningful units called chunks or chunk, which may be words, pictures, or numbers. Short-term memory capacity is limited as it can retain 5 to 9 chunks (Khamis, 2013). According to Miller famous theory, the retention chunks are named Miller constant such as 7+ or 2-. It can increase capacity and facilitate the recalling process if information that has been chunked (Miller, 2012). This theory contains three basic operations i.e. sensory recorder memory that receives learner stimuli and plays an important role in recognizing objects (Schunk, 2012). These stimuli must have the ability to activate attention through senses, such as color. Studies have revealed that colors can influence the interest, attention, and excitement level. It leads to emotional change that contributes to improving memory controlling processes. Information is stored as recognizable short time patterns (about a second to four seconds), and then they disappeared and replaced by other information. Finally, it converts into short-term memory (Khamis, 2013).

Another function is the short-term memory that represents the most important thinking components (Schunk, 2012). The selection process happens by moving information from sensory recorder memory to short-term memory. Moreover, it keeps information for a brief period (less than 20 seconds), if they are treated and strengthened through chunks process (Khamis, 2013). Lastly, the long-term memory function occurs after treating information in short-term memory, where it is converted into long-term memory, which is a permanent store for information (not limited capacity), it can be recalled with past events (Schunk, 2012). Information processes act through assimilation and integration with previous knowledge (Khamis, 2013). Later, researches have revealed that colors strategy helps in improving memory performance. It also has reported that different colors can improve information recalling from memory (Dzulkifli, \& Mustafar, 2013a).

\subsection{Theory of cognitive loud}

This theory is set as a trigger point for designing instructional message for the instructional designer. Hence it proves that if the cognitive loud is effective, education will not be an action. It is made for three types; first is real which represents the overlap level of the information and its interaction with other information. Second is the extraneous loud which is referred to as the 
unnecessary element impeding the learning process of an individual. These are considered as elements in designing message, such as using font types, and colors. The third type of loud is closely related to the way that designer facilitates the learning process for the learner, such as segmenting information, sequencing, and providing methods to understand like mind mapping.

Instructional designer has a role in designing instructional message by organizing information, in a way to facilitate retaining them easily. One way is coordinating information by using different colors to distinguish important points. Consequently, the instructional designer needs to reduce intrinsic and extraneous loud, and increase closely related loud (Kazdin, \& Blasé, 2011).

\subsection{Colors}

Colors are one of the amazing tools that add spiritual, attractive, and artful side for any design (Draz, 2015). Color is regarded as the value that is determined by an element of any material through reflected light (Shaltout, 2016). They are considered as the main information channel to the human cognitive system (Finn, White, \& Abdelbagi, 2011). In addition, it is an effective tool to attract attention, and it is defined as a strategy to support building guided-interface for certain designs. Colors are great tools to shape stimulus, as they attract learner eye to certain points assisting in the creation of the bond among elements which lead to increase learner's comprehension. The key to basic colors is to know what stimulus type that draws learner is' attention, the message that the sender wants to convey, and what color effects should be used. Shaltout (2016) define color as the value that determines the element of any material by reflected light, and there are associated definitions with color, such as prescription, color hue, or a characteristic that differentiates color from another. So, they are arranged respectively as a red color, green color, blue color etc. The color value is a characteristic that makes color light or dark, based on that green color is named as dark green and light green. Color saturation or color purity means the intensity of certain color and the degree of its radiation (Agoston, 2013). This feature is determined by the level of mixing certain color with black or white (Shaltout, 2016). These three definitions must be known by designers to enable them to utilize colors effectively in designing instructional message because they can attract learner's attention to important information (Akhmad, Sugandi, \& Nandi, 2018). As per the eye theory, there are three varying color sensations i.e. for red, green, and violet. Helmholtz theory confirms that human eye contains three cone cells linked with red, green and blue; Moreover, it mentions in Francorum theory confirming that basic colors are red, green, and purple (Agoston, 2013). In a practical way to study colors, Abdul Hadi \& Aldraash (2011) has presented his color circle that contains three basic colors (red, yellow, blue). Secondary colors result from the mixing of two basic colors with secondary colors (orange, green, violet) and then mix them to get new colors (Abdul Hadi \& Aldraash, 2011). All these color comprise of different color concepts such as pure, cold, warm, and harmony colors, along with color contrast phenomena, and neutral colors. 
Pure colors are red, orange, yellow, green, blue, and violet. These colors are classified as basic colors contain red, yellow and blue. Studies confirmed that these basic colors affect optical nerves; moreover, there are secondary colors that contain orange, green and violet (Agoston, 2013) and they are highly effective in education (Schunk, 2012). Whereas cold colors and warm colors are divided by researches that include red to greenish-yellow as cold colors, and warm colors include greenish-yellow to red (Agoston, 2013). Color Harmony is a convenient arrangement for colors by basic principles, and they include Duo harmony (complimentary), which is made of equal colors in the color circle (Shaltout, 2016). These colors show brightness and glimmering of other colors. When they are placed next to each other, they would be at the top of glowing and purity colors (Shlatter \& Levinson, 2013). Blue faces orange, and it is frequently used in sites, applications designs. Red faces green, and yellow faces violet (Agoston, 2013). These theories are also inclusive of color contrast which is defined as the intensity and clarity of colors, which is a key to motivate eye (Shlatter \& Levinson, 2013). It conveys receivers' sight from one place to another inside design (Draz, 2015). Examples of contrasting colors are yellow and purple. Generally, all colors in color circle are distinct. Warm colors are effective if they are placed in front, whereas cold colors are effective if they are placed at the back (Shlatter \& Levinson, 2013). They help to make an element clearer than the rest (Schunk, 2012), whereas contrast helps in distinguishing important information from the others (Schunk, 2012). Lastly, the theories also present neutral colors such as white, black and gray, which are well observed when they are placed as a background color (Dzulkifli, \& Mustafar, 2013b).

\subsection{Color strategies}

The first strategy "distinction strategy" is the difference between colors that lead to identifying color directly, quickly, undoubtedly, and easily. Second strategy "vision strategy" is defined as creating a strategy to benefit from color to increase visual ability from optical analyzing. Drawing attention is considered a bedrock to achieve this strategy because drawing attention is the origin of the communication process between image and background. Color strength emerges by its ability to be visible and shining amid the vast amount of texts and images. Color strength, distinguishing limit, text coherence, or images affect hugely on the recalling process, as well as, exposing period for the motivated learner in the encoding process. Stabilizing and repeating are important factors which should be relied on to develop the process of recalling (Shaltout, 2016).

The real question stands, what is the right way to start using colors? Or in other words, what is the appropriate way to use color? Which makes it work or not. Shlatter \& Levinson (2013) mention in their book that the first step in designing; is to locate what eye catches first, with taking into consideration the idea of saturated colors which attract an eye more than unsaturated colors. So, the main element in the design should be identified to match suitable color, recognizing elements that have a secondary role, and choosing a suitable contrast degree that complies with the major components. 


\subsection{Color Functions in instructional design}

Using color in instructional design has several functions. It distinguishes information among others, such as in Google Maps; red color refers to crowded streets, green color refers to the empty streets, and blue color indicates the road path; as well as, it uses other colors to illustrate the quantity, space, and size. They are also used in measurements and graphs to illustrate the different proportions of certain information. Additionally, the use of saturated color in maps help to indicate depth such as drilling, as the architect uses colors on blueprints to illustrate the details on the chart. Also, it adds an aesthetic side in prints, websites, and television programs. Logically, it links information, and help to clarify the difference among elements, as well as, highlighting them in the instructional message. It supports organizing information based on its importance and dividing information according to topics. Research has revealed that color facilitates and helps cognitive processes to perform their functions, and affecting the learning process. Colors help in understanding and storing information faster; moreover, retrieving and strengthening interaction between learners and content that make the learning process effective, efficient, and attractive eventually (Plass et al., 2014).

A unique experience in colors usage

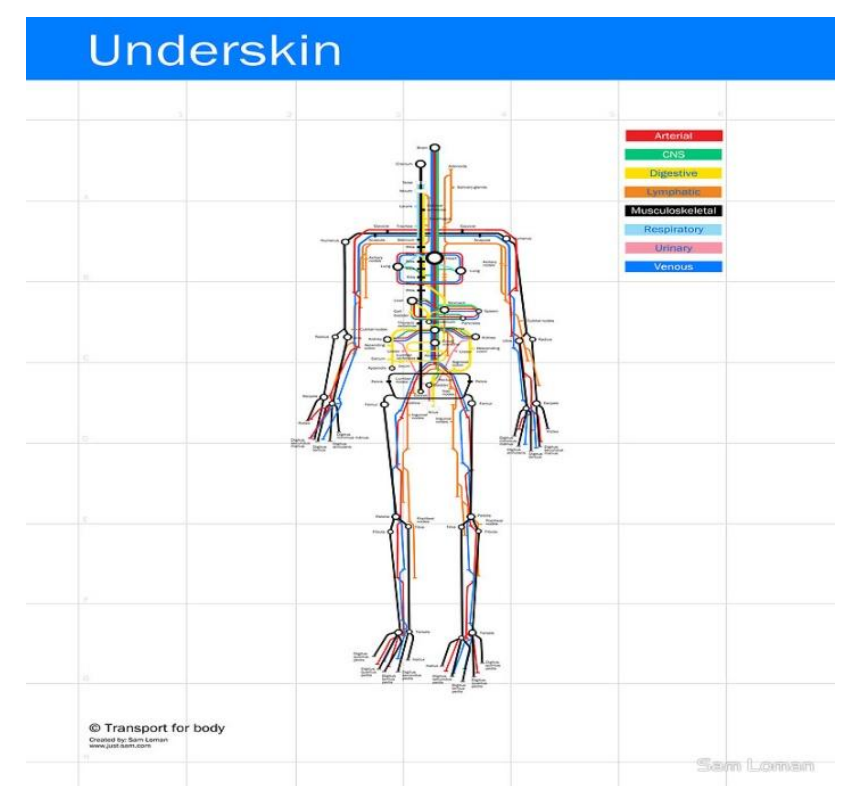

Figure 1. A unique experience in color usage

In 2010, the Sam Le Mans Onfrscan has designed infographic as shown in figure 1 , which highlights eight different systems inside the human body (digestive, respiratory, circulatory, etc.) and the designer has displayed main contact points using a figure like a subway map. The design was very impressive because 
colors were used to represent devices. Even though it were designed for medical community, but the design has spread across the Internet in many non-medical sites, such as Gizmodo, Behance, Vizworld, Aesthetics, Neatorama, Flickr and Infographics (Krum, 2013)

\subsubsection{Color and its association with memory}

The world today infuses a colorful environment, and most of the instructional message integrate this colorful aspect. The human mind cannot absorb this huge amount of visual information and treat them once, which makes color an important alert for learner enabling him to recognize information and interact effectively. (Finn, White, \& Abdelbagi, 2011) mention in his study that color is one of the most effective optical factors in encoding memory and increasing comprehension. Psychologists have found that memory works better if it is treated by colored alerts more than black and white because color attracts a sense of sight strongly that leads to better communication with the memory.

Rothen \& Meier (2010) checked memory and retrieving process for one student, they led him to read many colorful numbers, when they asked how you remembered all these numbers, he assured that colors made it easy to memorize them. Rich \& Karstoft (2013) stated that color has an immediate, relational response to the mind. Other studies have pointed out that "color is a vital factor in recalling information", and "the increased attention and interaction caused by color can improve retrieval process". Colors can improve memorizing process by increasing level of interest through enhancing excitement level. It happens when educational colorful objects are presented (Dzulkifli \& Mustafar, 2013a). Adding color to text will divide the information into classified patterns providing relevance amid these parts (Otto, 2013). Color has contributed to helping autistic patients and learning-difficulties patients in reading enhancement. (Allen, Evans, \& Wilkins, 2012) also helped in treating amnesia for a patient, which proves that it affects memory capabilities (Dzulkifli \& Mustafar, 2013b)

\subsection{Research in infographic and visual instruction}

The study of Sword (2012) study has aimed to build a list of comprehensive quality standards to instructional message design. It relies on the descriptive analytical approach, and it covered randomly sample of teaching staff in Saudi universities. An expert opinion survey was used in designing an instructional message in tertiary education. The study has concluded that beauty standards should have more interest, as well as, clarity in designing instructional message. This includes using text effectively and clearly with coordinated colors.

Wang \& Shen (2012) study has aimed to provide specific and practical recommendations for designing educational content for mobile education. The researcher used an experimental method and collected response from 113 students. Study tools were represented through evaluation form for mobilized education. Main results show that colors are utilized to distinguish elements inside a picture to gain attention on certain components, to match element logically, to choose colors that suit instructional message and objective audience, 
and to use saturated colors such as red and purple for gaining attention and creating emotional responses.

Oconnor (2015) analytical study aims to discover the role of colors with their contrast in the context of Gestalt theory, besides methods that are used to improve the effectiveness of visual communication design. Many designs were analyzed, and outcomes have shown that color plays an important role in the effectiveness of visual communication design. It supports the beauty of design, functionality-gaining attention, and change attention from one place to another inside the design. Colors have another role in the distinction between lines with detail, sense of depth, and movement and continuity, as well as, specifying main areas in the text such as titles and encoding basic information.

The study of Amal (2017) aims to determine standards of designing an educational infographic. The researcher access to standards of designing infographic in Arabic and foreign articles with revising previous researches. She listed these standards and classified them to educational and technical standards. The results of the study recommend using colors appropriately whether it stable, dynamic or interactive.

Abdul Rahman (2016) study aims to analyze and highlight the role of the infographic in the educational process, especially in building context formulations for certain text by studying the relationship between text and image; and determining their rules and standards that are associated with the text for pictures in education. In addition to analyzing infographic standards and their impact on the educational process. The study reveals infographic is benefited in the educational process by arranging information in a way to contribute to understanding and recalling process.

Ibrahim (2015) study aims to expose the effectiveness of using infographic technology as apart from a new visual design technique in the educational process. It's accredited to be used as a pilot curriculum on 68 students as a sample from the Department of Arts. The measure of independence and dependence were used to test the achievement in cognitive aspects for skills in designing visuals, as well as, applying a scorecard performance for skills of visual design, and scorecard for evaluating the product. Results have revealed that infographic has changed thinking way about complex information and added a new visual form in an attractive picture for the learner. Moreover, infographic design helps in increasing information treatment. Brain treats pictured information better than raw texts, because the mind handles images at once, while text addresses in written form (Liang, \& Liang, 2014). However, the results also indicated that attractive colors that were used in infographic presentation encourage learners to have better comprehension. Besides the idea of infographic ability to enhance the thinking process, linking information, organizing ideas, helping, and keeping information for the extra time.

The results indicated in Kang (2016) study intended to recognize some colors features on short-term memory for informational visualization. The basic colors are violet, red, yellow, and Cyan, which can attract attention and recall 
information. The study sample consisted of 83 people (40 males, 43 females) chosen deliberately between the ages 20-35. The researcher used an experimental method and collected data through a pair of infographic design that they have been designed as a supermarket consisting of 8 stores. These stores were distinguished with different colors like green, Cyan, purple, red, orange, yellow, blue, pink, and fuchsia. Participants were asked to remember 8 stores in 30 seconds.

Carpinell, Camps, \& Trottini (2008) experimental study aims to recognize children recalling level for colors. The study sample consisted of (50 children, 50 adults) male and female. They were randomly selected, and data were collected through special reference tests for the following colors: Violet, Bluish green, pink, greenish-yellow, orange from book Munsell for colors. The study has revealed that the test was bad for girls for greenish-yellow color, while it was good for women. Women remember violet color more than men, while girls remember orange and pink color better than boys. In contrast, boys remember green-bluish color more than girls.

Christopher et al (2015) examine the ability of color in effecting accounting subject to comprehend accounting topics by colors by utilizing experimental method on (79) students. Some of them have a background in accounting science and the other has not. Data were collected by using exams in the ACA International Company for training, and the exam was on accounting principles. The study has revealed that the teaching of accounting principles by using colors make the learning process easier in terms of comprehending and recalling.

The purpose of the study of Oconnor (2015) is to improve the effectiveness of visual designs by studying color contrast and color impacts on cognition based on gestalt theory. Study sample contains several designs, where the researcher used an analytical method to analyze these images. It has found color contrast support effectiveness of visual designs by feeling in depth, contrast, and draw attention to the keyword in the design.

Finn, White, \& Abdelbagi (2011) research has aimed to know the impact of using color on keeping the knowledge in the short and long term. Research sample covered 117 students from the Faculty of Medicine. Researcher has adopted a qualitative approach by using a pre-test session for teaching how to draw the abdominal pain for the two groups; the first group have learned drawing abdominal pain by using black color, and other groups have learned drawing abdominal pain by using colors, the study has revealed that no effective use for any color on keeping knowledge in short and long terms.

\section{Methodology}

For the study, the quasi-experimental designs have been conducted by the researchers. Based on this, the designing of instructional infographic has taken place. The design was intended to focus on evaluating the impact of the colors in designing the infographics. Mainly, on its impact on the recalling process of students. 


\subsection{Study Sample}

The study sample consisted of 87 female students from King Saud University enrolled in the 2018 academic year. Table (1) shows the number and percentage of female students for each major.

Table 1. Description of study sample according to major

\begin{tabular}{|c|c|c|}
\hline Major & Frequency & Percentage \\
\hline Art & 8 & $9,20 \%$ \\
\hline Psychology & 8 & $9,20 \%$ \\
\hline Computer Science & 24 & $27,60 \%$ \\
\hline Islamic studies & 20 & $23,00 \%$ \\
\hline Quranic Studies & 6 & $6,90 \%$ \\
\hline Special education & 21 & $24,10 \%$ \\
\hline Total & 87 & $100 \%$ \\
\hline
\end{tabular}

\subsection{Study Tools}

The researchers have designed a series of tests where each includes an infographic. In the first test, students are required to read several words in a specified time (i.e. one minute). Following it, they are required to write as many words as possible which were present in the infographic. In the second test, students are required to read several sentences in a specified time (one minute). Then, they are required to write as many sentences as possible which were read from the infographic. In the third test, students were asked to look thoroughly at the several images and person's names on specified time (one minute). Then students are asked to write as many as they can of those names that have been read in the infographic. In the fourth test, students were asked to have a closer look at the selected form that contains several different buildings at a specified time (three seconds). Then students are required to mention the largest number of buildings names that they had seen in the infographic. In the fifth test, students were asked to have a closer look at a form that contains several different boxes on a certain time (three seconds). Then students are required to mention the largest number of boxes names that they had seen in the infographic. 


\subsection{Validity, and Reliability}

Validity is considered when the preparation of the test is taken place. The validity tools were reviewed and evaluated by expert panel consist of three experts. Changes have been employed based on panel recommendations. Whereas, the verification of study reliability tools by using the test-retest method (major of stability), which tested 10 randomly selected students. with two weeks interval, the test was repeated in the same conditions. Based on the calculation for coefficient link factor between two applications and based on Pearson correlation coefficient results are scaled between $(0.82-0.87)$. Results are statistically acceptable to prove the reliability of study tools, a consistency factor is considered high if it reaches $(0.80)$ or more, considered medium from $(0.60$ to 0.70) and considered low if it is less than medium (Hassan \& Hashem, 2004).

\subsection{Data Analysis}

The researchers used a set of statistical methods; using SPSS software for data analysis. The data collected were analyzed through Pearson correlation, frequencies, percentages, mean, standard deviation, chi-square, contingency coefficient, one-way ANOVA and (LSD) test.

\section{Results}

The study used a Chi-square test for the analysis of the independent variable. By analyzing data (Table 2), it is clear there is a statistically significant correlation at the significance level $(0,05 \geq a)$ between the use of colors in designing instructional infographic, and the level of recall for students. The value of Chisquare reaches (55.807) and its statistical significance was less than the significance level $(0,05 \geq a)$. This Means differences or variation in the color leads to the variation in the level of recall among the students in relation to the designing of the instructional infographic. This result leads to two dependent variables, while also indicating that the recalling level for students relies on the colors that are being incorporated in the designing of the instructional infographic.

Table 2. Chi-square test results to measure the relationship between the use of colors in designing instructional infographic and the students' level of recalling

\begin{tabular}{|c|c|c|}
\hline \multicolumn{2}{|c|}{ Use of colors in designing instructional infographic } & Variables \\
\hline 55,807 & Ka value 2 $(\chi 2)$ & Level of recall \\
0,019 & Sig & \\
36 & Freedom Degree & \\
\hline
\end{tabular}

* Function at significant level 0.05 or less 
Table 3 results show that the value of coupling coefficient reaches (0372) between the colors in designing instructional infographic and recall level for the students. These are statistically significant highlighting that there is a coupling coefficient, and statistically significant relationship between using colors in designing instructional infographic, and recall level of the university students. These results demonstrated the acceptance of the research hypothesis specifying the statistically significant relationship at the $(0,05 \geq a)$ between the colors (red green - purple - Cyan) in designing instructional infographic, and recall level of students.

Table 3. Results in Contingency Coefficient test, it aims to measure the relationship between using colors designing instructional infographic and recall level for students.

\begin{tabular}{|c|c|c|}
\hline \multicolumn{2}{|c|}{ Colors in designing instructional infographic } & Variables \\
\hline 0,372 & Test Value & Recall Level \\
0,019 & Sig & \\
\hline
\end{tabular}

* Function at significant level 0.05 or less.

Means values and standard deviation were calculated for the student's performance in all tests, which were then compared by using One Way ANOVA test. The mean results in table (4) shows clear differences in students' performance based on study tools associated with the color variable. It has revealed that significant effect of the red color ranking it as first (8.34), followed by Cyan color mean (7.21), green color mean (6.95), and finally violet color with a mean of (6.63). Also, one way ANOVA has been used for assessing the significance of differences among mean of the students' performance for study tools based on variable color

Table 4. Means and standard deviations of student's performance on study tools based on the color variable

\begin{tabular}{|c|c|c|c|c|}
\hline \multicolumn{2}{|c|}{ variable } & mean & $\begin{array}{c}\text { Standard } \\
\text { deviation }\end{array}$ & Sorting \\
\hline \multirow{3}{*}{ Color } & red & $8,34$. & 1,90 & 1 \\
& Cyan & 7,21 & 1,84 & 2 \\
& Green & 6,95 & 2,26 & 3 \\
& Violet & 6,63 & 1,92 & 4 \\
\hline
\end{tabular}

One way ANOVA results are demonstrated in table 5. It reveals that there are significant differences among student's performances mean for study tools based 
on variable colors. Results in table 5 have shown a statistically significant value of $(P)$ as $(12.232)$ with a significance level $(0,000)$, and a statistically significant value at the significance level $(0,01 \geq \alpha)$.

Table 5. The results of One Way ANOVA for differences among student's performances mean for study tools based on colors

\begin{tabular}{|c|c|c|c|c|c|}
\hline $\begin{array}{c}\text { Sources of } \\
\text { variation }\end{array}$ & $\begin{array}{c}\text { Squares } \\
\text { Total }\end{array}$ & $\begin{array}{c}\text { Freedom } \\
\text { Degree }\end{array}$ & $\begin{array}{c}\text { mean } \\
\text { squares }\end{array}$ & $\begin{array}{c}\text { The } \\
\text { calculated } \\
\text { value of (q) }\end{array}$ & $\begin{array}{c}\text { Level of } \\
\text { significance }\end{array}$ \\
\hline \multirow{2}{*}{ Color } & 144,859 & 3 & 48,286 & 12,232 & 0,000 \\
& 1357,977 & 344 & 3,948 & & \\
\cline { 4 - 6 } & 1502,836 & 347 & \multicolumn{3}{|l}{} \\
& & & \multicolumn{3}{|l}{} \\
\end{tabular}

To find out the differences direction for any category from variable color categories, it has been used less significant difference test (LSD). Table (6) illustrates the results of comparisons among students' performance means for study tools based on colors. It reveals the differences between red color and other colors (Cyan, violet, green) with a particular inclination of red color.

Table 6: (LSD) Test to clarify the direction for differences significance among students' performance mean based on colors

\begin{tabular}{|c|c|c|c|c|c|c|c|}
\hline \multirow{2}{*}{ Color } & \multirow{2}{*}{$\mathbf{n}$} & mean & $\begin{array}{c}\text { Standard } \\
\text { deviation }\end{array}$ & \multicolumn{4}{|c|}{ Color } \\
\cline { 5 - 8 } & & & & red & Cyan & Violet & Green \\
\hline red & 87 & 8,34 & 1,90 & & 1,14 & $1,71$. & $1,39$. \\
\cline { 5 - 8 } Cyan & 87 & 7,21 & 1,84 & & & & \\
Violet & 87 & 6,63 & 1,92 & & & & \\
Green & 87 & 6,95 & 2,26 & & & & \\
\cline { 5 - 8 } & & & & & & & \\
\hline
\end{tabular}

\section{Discussion}

The results showed a strong coupling coefficient and statistically significant association among colors in designing instructional infographic, and recall level for students. They affirm that the use of colors influences recalling ability of the 
students. It is because human capabilities depend on recognizing color on eye and brain functions. This happens through transmitting from visual centers to the Bacillus cells and cones in the retina, where these stimuli each other to visual centers inside the brain affecting the individual memory (Draz, 2015). The researchers find colors not only has an aesthetical side but is also affecting, stimulating and attracting element. They play a functional role in comprehending and directing a receiver's sight towards a certain point. This is because they attract attention or distract in designing instructional message. The use of colors in a proper way allows the designer to tremendously affect the receiver ability that directly impacts, promotes, and develops, which sometimes at a certain point increases concerns on its usage in the message design. Generally, this is believed to improve the instructional design, and especially for designing instructional message in a way that supports the recalling process and information recalling for the learner. By that cognitive thinking would be achieved in Bloom's' taxonomy for recalling, comprehending, etc.

These align with the findings of Abu-Zeid and Salah (2016) which revealed that the use of Infographic in teaching is regarded as a type of multimedia which greatly influences the ideas presented. they also add that the perception through visual images is better than the cognition process by verbal language. It is because recalling of the visual memory is easier than recalling the verbal memory, which leads to the fact that recalling color (considered as a visual item) is an easy process. On the one hand, the results of this study match the findings of Christopher et al. (2015), which revealed that the use of color in teaching accounting has improved the students understanding as well as recall level. On the other hand, the present study results conflict with the research of Finn, White, and Abdelbagi (2011), which compares the two groups drawing of the abdominal pain; where one group has learned to draw abdominal pain using black color, and another group by using different colors. Their results reveal no effect of color on knowledge retention for both short and long term. Moreover, the researchers relate that to the fact that drawing is usually harder than texts in terms of retention and recall, thus it requires more complex mental processes.

The present study revealed that there exist differences in the recall level for students due to the use of variant colors (red - green - purple - Cyan) in the design of the instructional infographic. Observed differences are proved based on study tools for students' performance, and according to the difference of the colors. It is because each color has a different effect on human brains' ability for recalling memory. Such as human eye contains three types of conical cell, the first type responds to short wavelength (Cyan) color, the second corresponds to light with a medium wavelength (green)color, and the third one responds to long wavelength (red) color as stated in the Sagal theory, Thomas Ying theory, and Helmholtz Theory (Al-Qahtani \& Amer, 2008). Al-Qahtani and Amer (2008) have argued that warm colors, such as red and orange are stimulant and energizing colors; and cold colors such as blue, purple, and green are considered quietude and comfortable colors. Basic colors, (red, yellow and blue) affect eye nerves more than secondary colors (orange, green and Violet). This indicates that red and Cyan colors are better in terms of the memory recalling as compared to green and violet colors. This explains the result of current study 
were as learners receive stimuli and triggers, and they play an important role in recognizing materials such as color. These colors have different abilities to activate attention, which leads to the varying ability of the colors for recalling memory. Therefore, red color has occupied the first place in its ability to recall memory, followed by Cyan, Green, and violet -in order- for this study. This confirms that color closely links with the recalling process for a human being. If an Instructional designer does not use colors in designing instructional messages and software in a suitable way, then it would lead to the designing of ineffective instructional messages. Colors support recalling the information, which escalates its' use in instructional messages; and in many other places including educational media, educational software, educational websites, Books, photos and social media platforms.

Especially, when it comes to important information that a student is required to remember and use in educational drawing, as coloring arrows in the circulatory system to show bloodstream flow. However, it does not state that other colors lack the ability to impact the recalling process, but indicates that these follow red color in its ability on recalling process given their color order ranking (Cyangreen-violet). Therefore; the study recommends the usage of red color in instructional Infographic.

Many previous studies have addressed instructional message and infographics, as well as, color relationship with the recalling the process. The results of this study were discussed based on them, and agree with Wang and Shen (2012) results. It revealed that colors are used to differentiate image elements, and focus attention on specific elements, and link them logically. This necessitates the designer to choose colors that correspond to the instructional message, suit target audience, use highly saturated colors to attract attention, and create an emotional response.

The present study results are found parallel to the study of Birren (2016), which have revealed that colors have a special measurement as the text has. Such as excessive use of color will have the same effect as no color. Colors can increase reading speed and understanding the reader, and they are considered the most appropriate way to facilitate visual perception. In addition, it proved that blue color is used to represent culture, Internet, health, television, university, and travel; brown color is used to represent books; black color is used to represent cinema and events; the red color is used to represent automobile industry, fashion, music, nation and society; and green color is used to represent education and politics. The results of this study agreed with the results of the OConnor's (2015) study. This illuminates that colors play an important role in the effectiveness of visual communication design by supporting the beauty of the design. It highlights the color functional performance, as it attracts attention and shifts the direction of attention from one place to another within the design, as well as, distinguishing between lines and details. Besides, it supports the feeling of depth, movement, and continuity. It is used to identify key areas in the text such as headings, and to encode basic information. 
Amal (2017) confirms the present study findings revealing that basic technical standards for the infographic are to appropriately use the colors whether Infographic is constant, mobile, or interactive. Abdul Rahman (2016) study also supplements the current findings and clarifies that infographic strength point should be employed in the educational process by arranging information, in a way that contributes towards students understanding and recalling the process. The results of this study also agree with the results of Ibrahim (2015), which revealed that Infographic has changed the way of thinking about complex information and has added a new visual form in an attractive image of the learner. Its design increases the information to process, as the brain's treatment for visual information is less complicated than the raw text. Brain handles images at once in contrast with scripts, which are processed in a linear manner.

Results also indicated that using attractive colors in displaying Infographic, encourages the learners to understand information better because they are activating interest through senses. Studies have revealed that colors dramatically affect the attention and excitement levels and lead to an emotional change that contributes to enhancing controlling processes. They improve memory and store information by forming identified short -term patterns (about a second to four seconds), disappear, be replaced by other information and then finally it be converted into short-term memory (Thomson, 2012). Additionally, Infographic has the ability to enhance thinking, linking, and organizing information. The results of this study agree with OConnor (2015) which indicated that color and contrast improvement in the effectiveness of visual designs by releasing the feeling of depth and contrast, as well as, attracting attention towards the text keys or message in the design.

\section{Conclusion}

Based on previous outcomes, this study concludes that the use of color in the instructional design impacts the knowledge retention level of the students. It reveals that effective use of the basic color acts as a stimulus to trigger the memory and its ability to recall. The results show that there exists a significant relationship between the instructional design color and the recall level. Based on the results, the study recommends using colors in different ways to present an instructional message such as educational media, educational software, educational websites, images, books, social networking platforms, and other sites. In addition, it also suggests inviting instructional designers to take into consideration design technical standards for designing instructional message. Moreover, an analysis and evaluation continuity of instructional messages should take place to make it available for students in Saudi universities, to ensure their suitability for the targeted audience. There is a necessity for experts and specialist's assistance in designing instructional messages field to develop them and provide instructional messages, which consider the technical design standards that contribute to understanding and recalling processes. In addition, it also suggests considering different views and perspectives of faculty members and students on developing instructional messages that are designed from topics quality side, which includes development and modernization; holding seminars and workshops that promote awareness for faculty members about 
colors impacts in designing infographic on the recalling the process of students and maintaining recent developments in designing infographic field for continuous development. Although the study focused on only four colors, it has been proven that colors have an impact on students' recalling process; therefore, the researchers recommend studying different colors in different ways to present an instructional message such as Websites, pictures, books, social networking sites.

Also, the researchers suggest the application of the current study in different institutions in order to generalize benefiting while also assessing the difficulties that are faced when infographic is being used in the educational process.

\section{References}

Abdul Hadi al-Adly, \& Mohammed Aldraash. (2011). Color theory basics on design. Amman: Arab community library.

Abdul-Rahman, A. (2016). An analytical study for the infographic and its role in the educational process through context formulations. Journal of Research in Art Education and the Arts, 47, 1-17. retrieved on 23/8/2018.

Abu-Zeid., \& Salah. (2016). Using infographic in teaching geography to develop achievement and skills of visual thinking among secondary school students. Journal of Educational Society for Social Studies, 97, 138-198. Retrieved on 6/4/2018 $\mathrm{AH}$ from Dar Al Manthoumah database

Agoston, G. A. (2013). Color theory and its application in art and design (Vol. 19). Springer. Retrieved from https:// doi.org/10.1007/978-3-662-15801-2

Akhmad, R., Sugandi, D., \& Nandi, N. (2018). Infographic Design as Visualization of Geography Learning Media. In IOP Conference Series: Earth and Environmental Science (Vol. 145, No. 1, p. 012011). IOP Publishing. https://doi.org/10.1088/1755-1315/145/1/012011

Al Juhani, L. (2015). Design visual material: Applications and techniques. Riyadh Obeikan, 2000.

Al Seif, A. (2012). Proposal for designing instructional message in electronic undergraduate courses, Technology education, 1-50. Retrieved on 1/5/2018.

Al-Khalifa, H. (2013). Contemporary school curriculum. Riyadh Al Rushd Library.

Allen, P. M., Evans, B. J., \& Wilkins, A. J. (2012). The uses of color in optometric practice to ameliorate symptoms of visual stress. Optometry in Practice, 13(1), 1-8.

Al-Qahtani, \& Amer, L. (2008). Theories of color and lighting. Riyadh King Fahd Library

Amal. (2017). Standards of Instructional infographic design. Studies in tertiary, 35,61-96

Birren, F. (2016). Color psychology and color therapy; a factual study of the influence of color on human life. Pickle Partners Publishing.

Bruner, J. (2017). A study of thinking. Routledge. https://doi.org/10.4324/9781315083223

Carpinell, J., Camps, V., \&Trottini, M. (2008). Color memory in children. Color Research and Application, 33(5), 372-380. https://doi.org/10.1002/col.20433

Christopher, J., Phillips, M., Schertzer, S., Germann, A. (2015). An exploratory study of color accounting: a new way to teach and learn accounting. Journal of Higher Education Theory and Practice,15(7),77-85

Draz, J. (2015). Forensic Psychology. Africa Dar Amjad for Publishing and Distribution

Dzulkifli, M. \& Mustafar, M. (2013a). The influence of color on memory performance. Malaysian Journal of Medical Science, 20(2), 3-9. 
Dzulkifli, M. A., \& Mustafar, M. F. (2013b). The influence of colour on memory performance: A review. The Malaysian journal of medical sciences: MJMS, 20(2), 3.

Evans, R. (2016). Infographics on the brain. Computers in Libraries, 36(6),4-8.

Finn, G., White, P., \& Abdelbagi, I. (2011). The impact of color and role on retention of knowledge: a body painting study within undergraduate medicine. Anatomical Sciences Education, 4,311-317. https://doi.org/10.1002/ase.253

Flagg, B. N. (2013). Formative evaluation for educational technologies. Routledge. https:// doi.org/10.4324/9780203052181.

Hassan, \& Hashem, M., A. (2004). Statistical Manual in the data using spss Analysis. Riyadh: Al Rushd Library.

Ibrahim, H. (2015). The effectiveness of using infographic technology in development designing visual skills for students at Faculty of Art, independent and accredited at Faculty of Education. Arab Studies in Education and Psychology 62, 131-196, retrieved on 22/4/2018 from Dar Manthomh base.

Johnson, J. (2013). Designing with the mind in mind: simple guide to understanding user interface design guidelines. Elsevier. https:// doi.org/10.1145/2702613.2706667

Kang, X. (2016). The effect of color on short-term memory in information visualization. In Proceedings of the 9th International Symposium on Visual Information Communication and Interaction (pp.144-145). Taipei, Taiwan: National Taipei University. https://doi.org/10.1145/2968220.2968237.

Kazdin, A. E., \& Blase, S. L. (2011). Rebooting psychotherapy research and practice to reduce the loud of mental illness. Perspectives on psychological science, 6(1), 21-37. https://doi.org/10.1177/1745691610393527.

Khamis, M. (2013). Theory and Educational Research in Education Technology. Cairo: Dar Al Sahab for Publishing and Distribution.

Krum, R. (2013). Cool infographics: effective communication with data visualization and design. Chichester: John Wiley \& Sons.

Liang, C. T., \& Liang, C. (2014). Influential Factors and Their Correlation on Student Imagination. International Journal of Learning, Teaching and Educational Research, 2(1), 54-66.

Miller, A. I. (2012). Insights of Genius: Imagery and creativity in science and art. Springer Science \& Business Media. https://doi.org/10.7551/mitpress/3806.001.0001

Morrison, G.R., Ross, S.M., Kalman, H.K., \& Kemp, J.E. (2011). Instructional objectives. Chapter 5. In Designing effective instruction. (6th ed., pp106-133). Hoboken, NJ: John Wiley \& Sons.

Oconnor, Z. (2015). Color, contrast and gestalt theories of perception: the impact in contemporary visual communications design. Color Research and Application, 40(1),85-92. https://doi.org/10.1002/col.21858.

Otto, C. (2013). Writing with Color to Enhance Comprehension. In T. Bastiaens \& G. Marks (Eds.), Proceedings of E-Learn: World Conference on E-Learning in Corporate, Government, Healthcare, and Higher Education 2013 (p182-188). Chesapeake, VA: Association for the Advancement of Computing in Education (AACE).

Pettersson, R. (2013). Message design. Institute for Infology. https://doi.org/10.1080/23796529.2012.11674702.

Plass, J. L., Heidig, S., Hayward, E. O., Homer, B. D., \& Um, E. (2014). Emotional design in multimedia learning: Effects of shape and color on affect and learning.

Learning and Instruction, 29, 128-140. https:// doi.org/10.1016/j.learninstruc.2013.02.006.

Resnick, L. B. (2017). Toward a cognitive theory of instruction. In Learning and motivation in the classroom (pp. 5-38). Routledge. https://doi.org/10.4324/9781315188522-2. 
Rich, A. N., \& Karstoft, K. I. (2013). Exploring the benefit of synaesthetic colours: Testing for "pop-out" in individuals with grapheme-colour synaesthesia. Cognitive Neuropsychology, 30(2), 110-125. https://doi.org/10.1080/02643294.2013.805686

Rothen, N., \& Meier, B. (2010). Grapheme-colour synaesthesia yields an ordinary rather than extraordinary memory advantage: evidence from a group study. Memory, 18(3), 258-264. https://doi.org/10.1080/09658210903527308.

Rumelhart, D. E. (2017). Schemata: The building blocks of cognition. In Theoretical issues in reading comprehension (pp. 33-58). Routledge. https://doi.org/10.4324/9781315107493-4.

Schunk, D. H. (2012). Learning theories an educational perspective sixth edition. Pearson.

Shaltout., M. (2016). Infographic from planning to production, Riyadh: King Fahd Library

Shlatter, T., \& Levinson, D. (2013). Visual usability: principles and practices for designing digital applications. Burlington: Morgan Kaufman.

Simon, P. (2014). The visual organization: data visualization, big data, and the quest for better decisions. Chichester: John Wiley \& Sons.

Taha, F. (1994). Origins of modern psychology. Cairo: Egyptian Knowledge House

Thomson, A. (2012). Memory retention and the effects of background color in nontraditional students in online education settings. Retrieved from file:///C:/Users/rnass/Downloads/Memory_Retention_and_the_Effec.pdf.

Wang, M., \& Shen, R. (2012). Message design for mobile learning: Learning theories, human cognition and design principles. British Journal of Education Technology, 43(4), 561-575.doi: :10.1111.

Zghoul, I. (2015). Learning Theories. Amman, Jordan: Dar El Shorouk for Publishing and distribution. 